Emotion Review

\title{
Journeys to the Center of Emotion
}

\begin{tabular}{|r|l|}
\hline Journal: & Emotion Review \\
\hline Manuscript ID: & EMR-12-476.R1 \\
\hline Manuscript Type: & Commentary \\
\hline Date Submitted by the Author: & n/a \\
\hline Complete List of Authors: & Parkinson, Brian; University of Oxford, Experimental Psychology; \\
\hline Keywords: & appraisal, relational meaning, alignment, emotion \\
\hline Area/Discipline: & psychology \\
\hline & $\begin{array}{l}\text { Does appraisal co-ordinate emotional responses? Are emotions usually } \\
\text { reached via mental representations of relational meaning? This } \\
\text { commentary considers alternative causal routes in order to assess the } \\
\text { centrality of appraisal in the explanation of emotion. Implicit and explicit } \\
\text { meaning extraction can certainly help steer the course of emotion-related } \\
\text { processes. However, presupposing that appraisals represent the driving } \\
\text { force behind all aspects of emotion generation leads to inclusive } \\
\text { formulations of appraisal or restrictive formulations of emotion. }\end{array}$ \\
\hline & \multicolumn{2}{|l}{} \\
\hline
\end{tabular}

SCHOLARONE ${ }^{\text {w }}$

Manuscripts 
RUNNING HEAD: Center of emotion

\section{Journeys to the Center of Emotion}

Brian Parkinson, Oxford University, UK

Email: brian.parkinson@psy.ox.ac.uk

Key words: Appraisal, relational meaning, alignment, emotion 


\begin{abstract}
Does appraisal co-ordinate emotional responses? Are emotions usually reached via mental representations of relational meaning? This commentary considers alternative causal routes in order to assess the centrality of appraisal in the explanation of emotion. Implicit and explicit meaning extraction can certainly help steer the course of emotion-related processes. However, presupposing that appraisals represent the driving force behind all aspects of emotion generation leads to inclusive formulations of appraisal or restrictive formulations of emotion.
\end{abstract}




\section{Journeys to the Center of Emotion}

From where do emotions derive their distinctive qualities? What makes emotion emotional? And what makes fear fearful, joy joyous, and anger angry? These are key questions for appraisal theories just as they were for William James back in the $19^{\text {th }}$ century. Answers depend on which of the many aspects of emotion are treated as central distinguishing features.

For James (1898), what was central was the nature of internal experience; how an emotion felt subjectively to the person having it. Correspondingly, he focused on the causal impact of sensations from inside the body. For more recent psychological constructionist theorists, self-attributions (e.g., Schachter, 1964) or conceptualizations (e.g., Barrett, 2006) of internally perceived responses in emotional terms are central. Correspondingly, they explain emotion by reference to processes producing these representations of feeling. All these theories assume that getting to the center of emotion means getting to the point where the individual recognizes the emotional quality of experience. For appraisal theorists, this begs the question: what causes the pleasure, arousal, or other internal symptom that is then perceived, self-attributed, or conceptualised? Should explanation begin when the body reacts or before?

For Arnold (1960), what was central to emotion was an affectively toned perception of an object or event. Correspondingly, her explanation emphasised factors that gave this perception its emotional color. Likewise, Lazarus (1991) believed that the necessary condition for emotion was an apprehension of the personal significance or relational meaning of what is happening. Correspondingly, he ascribed causality to processes that led from person-environment transactions to this meaning. How transactions themselves came together from prior actions and orientations, events, contexts, and competences did not feature in this causal itinerary. Both Arnold and Lazarus assumed that getting to the center of emotion 
meant getting to the point where the individual recognizes the emotional significance of what is happening. Self-attributions of emotional state came later, if at all.

These theorists work backwards from the part of emotion they want to explain, and make inferences about what stages the mental system must have passed through in order to get there. They all treat some fixed point in an unfolding emotional trajectory as the destination of the causal process (Ellsworth, this issue). What happens before this point is treated as the explanatory process that specifies the nature of the emotion and determines its future course.

Treating one aspect of emotion as central helps delimit the task of explanation. Instead of having to catalog all processes underlying complex unfolding syndromes and interactions between their various components in one go, researchers can focus on better signposted causal paths leading to more circumscribed outcomes. In this commentary, I will consider how successfully appraisal theories such as the reformulated version presented by Moors (this issue) specify the processes that lead to the circumscribed outcome of relational meaning.

The main disadvantage of these centralized approaches is that other, supposedly noncentral aspects of emotion are underemphasized or ignored. My commentary also discusses whether appraisal outcomes genuinely are central to specification of all aspects of emotion episodes.

\section{Starting Points}

Specifying precisely where unfolding events begin is often tricky. Any emotion is determined by interlocking chains of more or less proximal causal events. Although distal causes arising from natural selection, cultural history, and socialization are widely acknowledged (Parkinson, 2012), most psychological research focuses more directly on personal and situational factors operating proximally in the immediate situation. 
Even within this limited time-frame, appraisal theorists disagree about what the starting point for the causal path leading to emotion might be. During the affective primacy debate, both Lazarus (1984) and Zajonc (1984) took it for granted that emotions started with some momentary stimulus, and only disagreed about the route from this stimulus to the emotion. Some appraisal theorists continue to assume that emotions are triggered by “stimuli" (e.g., Moors, this issue), but others now refer to events, situations, or personenvironment transactions instead. In Lazarus's (1991, p. 121) words: “person-environment relationships must be sensed and evaluated personally (appraised) by an individual to generate emotions."

Why this shift? The main reason is that the appraisals characterizing many emotions are directed at relational meaning, derived from the person's position and trajectory within the environment ("she questioned my competence in front of my boss"). This implies that emotional significance partly depends on matches or mismatches between perceived events and an individual's concerns. Information specifying these matches and mismatches is rarely contained in a single momentary stimulus, whether internal or external. If appraisal is to mediate effects on emotion, it needs to take into account the person's orientation to what is happening.

But if emotions consolidate in dynamic attunement with the developing structure of unfolding transactions, how great an explanatory gap is left for appraisal to bridge? When people make on-line adjustments to events, they likely arrive at emotional orientations cumulatively as those events unfold. Arguably, then, meaningful emotions may be in place before appraisal can take a configured event as its object (e.g., Parkinson, 2001a). If so, appraisal merely adds some private registration of an orientational pattern that has already coalesced. Correspondingly, if explaining emotion involves getting to an integrated relational 
meaning, then only a small part of the causal process occurs after the transaction has consolidated.

More generally, the search for any momentary starting point implies a baseline state of zero emotion. Some special ingredient (or combination of ingredients) is thus required to transform this non-emotional state into an emotional one. As discussed above, the nature of this ingredient depends on what theorists see as central to emotion. However, if emotions emerge from contextually embedded lines of action, such a zero point becomes difficult to isolate, and more emotion ingredients will already be in place prior to arrival at the allotted causal destination.

\section{Routes to Relational Meaning}

According to Lazarus's (1991) version of appraisal theory, the immediate proximal cause of any emotion is apprehension of appraisal patterns characterised as core relational themes. Similarly, Moors (this issue) argues that "[t]he appraisal process causes an appraisal output, which is a component of emotion. This appraisal output, in turn, causes the other components of emotion (action tendencies, physiological responses, expressive behavior, and feelings)." How then do people get to this appraisal output or core relational theme?

The answer is: by a variety of causal routes, but not an infinite variety. Moors (this issue) specifies appraisal as including only "processes that deal with appraisal variables (e.g., goal congruence, coping potential, agency)” (p. xxx). However, as she acknowledges, this definition in terms of content invites dispute about what counts as an appraisal variable.

As for process, Moors stipulates that " $[\mathrm{m}]$ echanisms that are not mediated by or do not result in a representation do not count as potential mechanisms underlying appraisal" (p. xxx). By representation, Moors means "something that is invoked to explain variable (as opposed to fixed) input-output relations" (p. xxx). According to this criterion, "primitive evaluative perceptions” (Lazarus, 1984, p. 124), sensorimotor processes (Leventhal \& Scherer, 1987), 
and associations (Smith \& Kirby, 2001) only count as appraisal processes if they get an individual to a "representation of appraisal values" and if they do not dictate a particular response to a stimulus or transaction. Taken together, Moors' content and process criteria imply that appraisal necessarily explains any non-reflexive reaction to implicitly or explicitly apprehended personal significance. Whether all instances of emotion fit these specifications also depends on preferred definitions.

Moors' criteria specify no upper limit to the level at which appraisal processes might operate, and explicitly accommodate top-down conceptual processes (e.g., Leventhal \& Scherer, 1987). Would explicit systematic reasoning about matters of personal significance count as appraisal too? Such reasoning certainly involves representation of appraisal values and implies variable input-output relations. What if someone decided after careful reflection that an emotional reaction was warranted? Would that qualify as appraisal if the resulting attempt to work up emotion was successful?

Although Moors' formulation of appraisal is more restrictive than Lazarus's earlier one, it is still inclusive enough to cover a wide range of different routes to relational meanings. In practice, it would be complicated to track all possible algorithmic or implementational instantiations of the functional process connecting inputs to meaningful outputs (cf. Marr, 1982). Appraisal continues to be an elastic construct (Scarantino, 2010; see also Parkinson, 1995) that can be compressed to pass through the narrowest of openings or stretched round the tightest of explanatory corners. Questions remain about whether appraisal theory specifies a clear causal route or merely maps out a start-point and destination that must be traversed in one way or another. 


\section{Centrality of Relational Meaning}

\section{Appraisal-emotion associations}

Both Lazarus (1991) and Moors (this issue) argue that arriving at relational meanings (appraisal outcomes) leads to emotional outputs. The postulated centrality of these relational meanings depends on them showing tight associations with other aspects of emotion. Consistent with this conclusion, several studies have demonstrated that emotional interpretations of imagined, experienced, or recalled events are often associated with consistent reports of these events' appraised meanings (see Parkinson, 1997, for a review). Participants reporting anger, for example, also tend to report that an external agency is accountable for some motive-inconsistent event.

At minimum, this evidence shows that differential emotion concepts relate to differential appraisal concepts. This is not a trivial finding given that previous studies had suggested that two affect dimensions (pleasure and arousal) capture most conceptual differences between emotions (e.g., Russell, 1980). Whether the additional information provided by appraisal dimensions reflects intrinsic qualities of the subjective feeling or extrinsic features of the surrounding episode need not concern us here (e.g., Russell, 2003). What is important is that the appraisal studies indicate a way of differentiating emotions that does not depend on distinctive experiential essences or psychophysiological specificity.

However, subsequent evidence suggests that associations between reported appraisals and emotions depend on how episodes are sampled. Asking people to present emotional experiences for the purposes of psychological investigation often encourages them to focus on reasonable and justifiable examples. Conventional appraisals are more likely to characterize these selectively reported emotions. Correspondingly, participants instructed to recall unreasonable instances of guilt and anger show lower levels of the predicted appraisals (Parkinson, 1999). Parkinson, Roper, and Simons (2009) neutralised implicit demands by 
collecting prospective reports of both reasonable and unreasonable instances of anger. Again, relatively lower ratings of other-accountability accompanied less reasonable instances.

Variations in appraisal-emotion associations occur across persons as well as across situations. For example, using diary methods, Nezlek, Vansteelandt, Van Mechelen, and Kuppens (2008) found individual differences in appraisals associated with six emotions.

The above evidence apparently undermines the centrality of relational meanings as coordinators of emotional outcomes. However, interpretation depends on the validity of selfreport measures. Critics of appraisal theory argue that close associations between appraisal and emotion ratings may reflect prototype-biased misrepresentations (e.g., Parkinson \& Manstead, 1992). Correspondingly, appraisal theorists might contend that weak associations merely reflect participants' failure to detect non-conscious, implicit, or evanescent appraisal processes and their representational outputs. Although people may sometimes fail to report other-blame appraisals in connection with reported anger, for example, they may still have registered other blame at some level. Alternatively, they may have mislabeled "frustration" as "anger."

Resolving these interpretational issues requires agreement on criteria for validating implicit measures of appraisal and emotion. Validation is not facilitated by current inclusive formulations of the appraisal concept, or persistent disagreements about emotion definitions (e.g., Bard \& Cornelius, 2007).

\section{Temporal sequences}

None of the evidence presented in the previous section addresses temporal priority. Appraisals reported in the above studies might just as easily be components or consequences of emotion as antecedents. At what point in a developing emotion episode are relational meanings apprehended? If they only consolidate alongside the emotion itself, then they cannot be central to co-ordination of its other components. 
Establishing when relational meanings and emotions emerge in rapidly changing realtime transactions is difficult, partly because of the limited temporal resolution of most available measures. Although reaction-time studies suggest that participants infer emotional meaning from situation descriptions more quickly than appraisal meaning, Siemer and Reisenzein (2007) suggest that this simply shows that appraisal inferences have become automatized. How such findings relate to on-line meaning extraction in personally involving situations is another issue (Parkinson, 2007). Even if valid measures of momentary implicit appraisals can be applied as transactions unfold, it would still be necessary to show that the indexed processes emerged prior to implicit traces of developing emotions.

And even if temporal precedence could be established in any particular instance, this would not demonstrate that appraisals always came first. There may be no fixed point at which appraisal values are registered, with relational meanings preceding, paralleling, or following emotions under different circumstances. Thinking about things may lead to recognition of previously undetected personal implications that in turn provoke an emotional reaction (antecedent appraisal). Equally, an unfolding episode may lead to a growing realisation of personal significance that is tracked in real time by a growing emotional reaction (parallel appraisal, see Ellsworth, this issue). Alternatively, combinations of factors such as tiredness, attentional demands, physical resistance, and other people's unfolding orientations may jointly entrain response patterns whose emotional implications in turn draw attention to personally significant events (subsequent appraisal). In such situations, individuals might even become recognizably emotional without ever getting to the point of apprehending relational meaning at any level (absent appraisal). More generally, if there is variability in the temporal sequence of appraisal and emotion, then explaining appraisal outcomes cannot explain all instances of emotion. 


\section{Causal precedence}

Instead of tracking the time course of unfolding emotion episodes, investigators can use experimental manipulations to establish appraisal's causal priority. Findings indicate that manipulating appraisal-relevant information (or its processing) can influence autonomic and neural responses, facial activity, or self-reported subjective experience (see Scherer, this issue).

Although there is scope for debate about whether the active ingredient of indirect appraisal manipulations is necessarily "appraisal," the causal role of these manipulations in inducing emotion-related outcomes is not in dispute. However, manipulations of variables other than appraisal can also influence comparable outcomes. For example, sudden changes in stimulation reflexively induce autonomic responses. Eyes widen or are drawn towards vivid or high-contrast stimuli regardless of how they are appraised. Exertion raises metabolic activity, and physically resistant objects increase muscular tension. Moving from momentary stimuli to unfolding events, objects are tracked by direct adjustments of head position and gaze direction. Faces dynamically mimic or complement other people's facial movements. Young infants show temporally articulated expressive responses at ages before their cognitive development should permit the appraisals supposedly required for the corresponding emotion (e.g., Draghi-Lorenz, Reddy, \& Costall, 2001). Many of these influences involve stable rather than variable input-output relations and bypass appraisal representations, raising the possibility that at least some components of emotion can arise independently of appraisals as defined by Moors (this issue).

Emotion-related outcomes are also produced by processes operating at a higher and more strategic level than accommodated within most contemporary appraisal theories. For example, autonomic and facial responses are enhanced as well as suppressed by regulatory processes (e.g., Mauss, Bunge, \& Gross, 2007). Facial expressions and subjective reports are 
influenced by anticipated interpersonal consequences, even after controlling for appraisal ratings (e.g., Leary, Landel, \& Patton, 1993; Parkinson, 2001b).

Of course, this evidence no more shows that emotions are typically determined and fully co-ordinated by adjustive or strategic processes than the appraisal-consistent evidence shows that emotions are typically determined and fully co-ordinated by appraisals. Both kinds of evidence merely demonstrate that the causal processes in question might contribute to emotion under some circumstances. Showing that a wide range of appraisals can cause a wide range of emotional outcomes certainly strengthens the plausibility of centralized appraisal accounts. Similarly, showing that processes other than appraisal can cause corresponding effects raises the possibility that these processes too could come together to yield patterned emotional responses.

Appraisal theorists might account for any such anomalies in three ways. First, they might deny that appraisal-independent outcomes are genuinely “emotional” (e.g., Lazarus, 1984). However, such a strategy risks circularity if the main reason for denying emotionality is the absence of appraisal (Zajonc, 1984).

Second, appraisal theorists might acknowledge that real emotions are produced but reinterpret the effective causal factors as "appraisals" (Lazarus, 1984; Moors, this issue). To avoid circularity, such a strategy requires the application of strict exclusion criteria for the appraisal concept. None of those so far suggested seem to exclude all of the causal processes mentioned above. Even "recognition of action affordances" (Moors, Ellsworth, Scherer \& Frijda, this issue, p. xxx) would not count as appraisal by Moors' (this issue) own criteria if Gibson's (1979) rejection of cognitive mediation is taken seriously. According to his ecological approach, the dynamic information directly picked up as actors operate on, and move through, the environment specifies meaning without the intervention of representational 
processes. Similarly, emotional actions and orientations may be guided directly by registration of what the social environment currently affords.

The third way involves taking anomalies seriously rather than seeking to explain them away (see also Moors, this issue). In other words, theorists might simply accept that both appraisal and other processes can generate emotional outcomes. If so, then appraisal may not be central to emotion causation across all relevant episodes. The main disadvantage of this third way seems to be a loss of parsimony. But parsimony achieved only by restricting formulations of "emotion" or by stretching the formulation of "appraisal" is not really parsimony at all.

\section{Course Correction}

Does explaining emotion necessarily involve explaining individuals' apprehension of relational meaning or their private recognition of the quality of experience? Part of the answer depends on how theorists formulate the phenomenon that they are trying to explain. If theorists conceive of emotions as individual experiences with distinctive subjective qualities, then it seems necessary to detect whatever is distinctive about subjective experience in order to become emotional. If theorists conceive of emotions as functional states of action readiness oriented to the individual's concerns, then it seems necessary for individuals to detect the concern-relevance of what is happening before an appropriate emotion can be output. However, as Scherer (this issue) shows, this need not involve extracting any centralized or integrated relational meaning. Instead, functional attunement may be achieved cumulatively by checking more delimited transactional parameters in sequence.

Even in Scherer's (this issue) model, the individual's mental system must register concern-relevance stage-by-stage in order to produce a co-ordinated emotional response. In my view, further decentralization is possible. If emotions are conceptualized as relational orientations then they depend on any processes that determine the focus of attunement, 
motivation, and action. These processes need not be localized within a delimited time-frame compressed between a pattern of detected transactional information and a specific emotional reaction to that information. Instead, unfolding contextualized actions always already involve directed activity whose focus adjusts on-line as transactions unfold. In effect, some aspects of action readiness may already be in place before the specific event that crystallizes a more articulated emotion. These earlier antecedents are not simply sources of appraisal information for a proximal emotion-determining process; they are the part of the directed activity that constitutes relational orientations.

From a relation-alignment perspective (e.g., Parkinson, 2008), another kind of decentralization is also possible. Emotions are not solely co-ordinated by internal mental processes, but instead depend on causal networks distributed across actors and their shared responsive environments over time (e.g., dynamic systems, Lewis \& Liu, 2011). We pick up other people's enthusiasm while working alongside them on some common task. We mutually intensify our struggle against an antagonistic group. We adjust to each other's orientation or strategically communicate our social motives (e.g., Fridlund, 1994). In either case, focusing on the meanings we extract from unfolding events fails to capture all of the important forces that give episodes their emotional color.

Should we set a course for the center of emotion at all? I have no doubt that useful information can be derived from studies that map out causal paths from transactional information to representations of appraisal values, as well as emotion-related outcomes of other kinds. Exploration of the ways in which individuals get to the point of implicitly or explicitly characterizing their experience in emotional terms is also important. But marking out either route leaves other avenues and prospects unexplored. If we want to get to real-life, real-world, embodied and relational emotions, then we should never be satisfied with individualized cognitive representations of either transactions or emotions themselves. 


\section{References}

Arnold, M. B. (1960). Emotion and personality (volume 1): Psychological aspects. New York: Columbia University Press.

Bard, K., \& Cornelius, R. (Eds.) (2007). The definition issue (Vol. 22 of Emotion Researcher). Poughkeepsie, NY: ISRE publications.

Barrett, L. F. (2006). Solving the emotion paradox: Categorisation and the experience of emotion. Personality and Social Psychology Review, 10, 20-46.

Draghi-Lorenz, R., Reddy, V., \& Costall, A. (2001). Re-thinking the development of "nonbasic" emotions: A critical review of existing theories. Developmental Review, 21, 263-304.

Fridlund, A. J. (1994). Human facial expression: An evolutionary view. San Diego, CA: Academic Press.

James, W. (1898). The principles of psychology (Vol. 2). London: Macmillan.

Lazarus, R. S. (1984). On the primacy of cognition. American Psychologist, 39, 124-129.

Lazarus, R. S. (1991). Emotion and adaptation. New York: Oxford University Press.

Leary, M. R., Landel, J. L., \& Patton, K. M. (1996). The motivated expression of embarrassment following a self-presentational predicament. Journal of Personality, 64, 619-636.

Leventhal, H., \& Scherer, K. R. (1987). The relationship of emotion to cognition: A functional approach to a semantic controversy. Cognition and Emotion, 1, 3-28.

Lewis, M. D., \& Liu, Z. (2011). Three time-scales of neural self-organization underlying human basic and non-basic emotions. Emotion Review, 3, 416-423.

Marr, D. (1982). Vision: The philosophy and the approach. In D. Marr (Ed.), Vision: A computational investigation into the human representation and processing of visual information (pp. 103-126). New York: Freeman. 
Mauss, I. B., Bunge, S. A., \& Gross, J. J. (2007). Automatic emotion regulation. Social and Personality Psychology Compass, 1, 146-167.

Nezlek, J. B., Vansteelandt, K., Van Mechelen, I., \& Kuppens, P. (2008). Appraisal-emotion relationships in everyday life. Emotion, 8, 145-150.

Parkinson, B. (1997). Untangling the appraisal-emotion connection. Personality and Social Psychology Review, 1, 62-79.

Parkinson, B. (1999). Relations and dissociations between appraisal and emotion ratings in reasonable and unreasonable anger and guilt. Cognition and Emotion, 13, 347-385.

Parkinson, B. (2001a). Putting appraisal in context. In K. R. Scherer, A. Schorr, \& T. Johnstone (Eds), Appraisal processes in emotion: Theory, research, application (pp. 173-186). Oxford University Press.

Parkinson, B. (2001b). Anger on and off the road. British Journal of Psychology. 92, 507526.

Parkinson, B. (2007). Getting from situations to emotions: Appraisal and alternative routes. Emotion, 7, 21-25.

Parkinson, B. (2008). Emotions in direct and remote social interaction: Getting through the spaces between us. Computers in Human Behavior. 24, 1510-1529.

Parkinson, B. (2012). Piecing together emotion: Sites and time-scales for social construction. Emotion Review, 4, 290-298.

Parkinson, B., \& Illingworth, S. (2009). Guilt in response to blame from others. Cognition and Emotion, 1589-1614.

Parkinson, B., \& Manstead A. S. R. (1992). Appraisal as a cause of emotion. Review of Personality and Social Psychology, 13, 122-149.

Parkinson, B., Roper, A., \& Simons, G. (2009). Appraisal ratings in diary reports of reasonable and unreasonable anger. European Journal of Social Psychology. 39, 82- 
87.

Russell, J. A. (1980). A circumplex model of affect. Journal of Personality and Social Psychology, 39, 1161-1178.

Russell, J. A. (2003). Core affect and the psychological construction of emotion. Psychological Review, 110, 145-172.

Scarantino, A. (2010). Insights and blindspots of the cognitivist theory of emotions. British Journal for the Philosophy of Science, 61, 729-768.

Schachter, S. (1964). The interaction of cognitive and physiological determinants ofemotional state. In L. Festinger (Ed.), Advances in experimental social psychology (Vol 1, pp. 49-80). New York: Academic Press.

Siemer, M., \& Reisenzein, R. (2007). The process of emotion inference. Emotion, 7, 1-20.

Smith, C. A., \& Ellsworth, P. C. (1985). Patterns of cognitive appraisal in emotion. Journal of Personality and Social Psychology, 48, 813-838.

Smith, C. A., \& Kirby, L. D. (2001). Breaking the tautology: Toward delivering on the promise of appraisal theory. In K. R. Scherer, A. Schorr, \& T. Johnstone (Eds.), Appraisal processes in emotion: Theory, methods, research (pp. 121-138). New York: Oxford University Press.

Zajonc, R. B. (1984). On the primacy of affect. American Psychologist, 39, 117-123. 


\begin{abstract}
Author Note
Work on this article was conducted as part of project EROS (Emotion Regulation of Others and Self, RES-060-25-0044) and supported by the Economic and Social Research Council, UK.
\end{abstract}

